\title{
La fortuna del 'Secolo d'Oro', per Marco Lombardi, a cura di B. INNOCENTI
}

\section{Monica Pavesio}

\section{(2) OpenEdition}

\section{Journals}

\section{Edizione digitale}

URL: https://journals.openedition.org/studifrancesi/22611

DOI: 10.4000/studifrancesi.22611

ISSN: 2427-5856

\section{Editore}

Rosenberg \& Sellier

\section{Edizione cartacea}

Data di pubblicazione: 1 avril 2020

Paginazione: 170

ISSN: 0039-2944

\section{Notizia bibliografica digitale}

Monica Pavesio, «La fortuna del 'Secolo d'Oro', per Marco Lombardi, a cura di B. InNocentI», Studi Francesi [Online], 190 (LXIV | I) | 2020, online dal 01 avril 2020, consultato il 03 août 2021. URL: http:// journals.openedition.org/studifrancesi/22611 ; DOI: https://doi.org/10.4000/studifrancesi.22611

Questo documento è stato generato automaticamente il 3 août 2021.

\section{cc) (i) $\odot$}

Studi Francesi è distribuita con Licenza Creative Commons Attribuzione - Non commerciale - Non opere derivate 4.0 Internazionale. 


\title{
La fortuna del 'Secolo d'Oro', per Marco Lombardi, a cura di B. INNOCENTI
}

\author{
Monica Pavesio
}

\section{NOTIZIA}

La fortuna del 'Secolo d'Oro', per Marco Lombardi, a cura di B. INNOCENTI, Firenze, University Press, 2018, $156 \mathrm{pp}$.

1 Il volume, dedicato a Marco Lombardi, specialista del teatro francese secentesco e settecentesco, si configura come un dialogo intorno al tema del Grand Siècle inteso come Secolo d'oro dalla valenza europea e della sua fortuna nei secoli successivi. Un libro polifonico che presenta il dialogo tra specialisti di diverse discipline - il francesista, l'ispanista, l'italianista, lo storico del teatro - che sono lo specchio, come asserisce Barbara INNOCENTI nell'introduzione, della poliedricità di interessi dello studioso a cui il volume è dedicato.

2 Il volume si apre con un saggio di Daniela DALLA VALLE (Strumenti e assimilazioni per ampliare il Secolo d'Oro: Barocco, Manierismo, pp. 17-25) sulla ridefinizione del Grand Siècle su un arco cronologico più ampio che abbraccia autori, opere, orientamenti ignorati fino a pochi decenni fa. Grazie alla compenetrazione tra Barocco, Manierismo e Classicismo, francesi ed europei, il Grand Siècle, periodo che comprendeva solo gli anni del regno di Luigi XIV, si è dilatato, arricchito, differenziato fino a poter essere considerato come il Secolo d'Oro della letteratura francese. Direttamente collegati a questo primo saggio sono i due articoli di Laura Dolfi (Tirso e i "Cigarralles de Toledo". Un esempio di ingegnosità barocca, pp. 27-40) e di Maria Grazia PROFETI (Teatro aureo e pubblico italiano, pp. 43-50) sul teatro del Secolo d'Oro spagnolo. Sono incentrati sulla Francia del XVII secolo gli studi di Teresa MEGALE sui viaggi di attori italiani in Francia (Un napoletano a Parigi: Michelangelo Fracanzani-Polichinelle, eroe della sazietà, pp. 53-57) e di Renzo GUARDENTI sull'apporto del teatro italiano nell'iconografia teatrale secentesca (Immagini del teatro del Grand Siècle. Note sull'iconografia teatrale del Seicento francese, pp. 73-83). 
3 Assumendo un'ottica settecentesca, Michel DELON (Grandeur et petitesse de la petite maison, pp. 59-72) mette in discussione la Grandeur del Secolo di Luigi XIV, aprendola ad altre istanze contrarie. Enza BIAGINI, nel suo Torquato Tasso alla maniera di De Sanctis (pp. 87-101), ripercorre le tappe europee della drammatizzazione, nel corso del xIX secolo, di episodi della vita del grande poeta italiano. Chiude il volume un saggio di Michela LANDI sulla "modernità" di Molière e una delle sue pièces più celebri e controverse Il Misantropo (Modernità di Molière, pp. 109-131). In appendice, la trascrizione di un originale documento sulla morte di Luigi XIV, rivenuto da Barbara Innocenti negli archivi pistoiesi. Un ricco apparato iconografico ed un indice dei nomi concludono il volume. 